Article

\title{
Water Adsorption on the $\beta$-Dicalcium Silicate Surface from DFT Simulations: a Dual Nucleophilic- Electrophilic Interaction
}

\author{
Qianqian Wang, ${ }^{1}$ Hegoi Manzano, ${ }^{2 *}$ Iñigo López-Arbeloa, ${ }^{3}$ and Xiaodong Shen ${ }^{1 *}$ \\ 1 State Key Laboratory of Materials-Oriented Chemical Engineering, College of Materials Science and \\ Engineering, Nanjing Tech University, Nanjing 210009, China. \\ 2 Condensed Matter Physics Department, University of the Basque Country, UPV/EHU, 48080, Bilbao, Spain \\ 3 Molecular Spectroscopy Laboratory, Department of Physical Chemistry, University of the Basque Country, \\ UPV/EHU, 48080, Bilbao, Spain \\ * Correspondence: hegoi.manzano@ehu.eus, xdshen@njtech.edu.cn
}

\begin{abstract}
Ca}_{2} \mathrm{SiO}_{4}$, or $\beta-\mathrm{C}_{2} \mathrm{~S}$ in cement chemistry notation) is one of the most important minerals in cement. An improvement of its hydration speed would be the key point for developing environmentally friendly cements with lower energy consumption and $\mathrm{CO}_{2}$ emissions. However, there is a lack of fundamental understanding on the water $/ \beta-C_{2} S$ surface interactions. Therefore, in this work we aim to understand the water adsorption and dissociation mechanism on the $\beta$ - $C_{2} S$ (100) surface using density functional theory (DFT) calculations. Our results indicate that thermodynamically favorable water adsorption process takes place in several surface sites, with a broad range of adsorption energies $(-0.78$ to $-1.24 \mathrm{eV})$, depending on the particular water conformation and surface site. To clarify the key factor governing the adsorption, the electronic properties of water at the surface sites were analyzed. The partial density of states (DOS), charge analysis, and electron density difference analyses suggest a dual interaction of water with $\beta-C_{2} S$ (100) surface: a nucleophilic interaction of the water oxygen lone pair with surface calcium atoms, and an electrophilic interaction (hydrogen bond) of one water hydrogen with surface oxygen atoms, being the first one the stronger interaction. Hence, we suggest that $\beta-C_{2} S$ hydration could be enhanced by introducing chemical or structural changes that increase both the electronegative/positive character of the surface.
\end{abstract}

Keywords: Belite, Hydration, Density Functional Theory, Water Adsorption, Calcium Silicate

\section{Introduction}

Hydration and dissolution of crystals have a profound impact on a broad range of scientific and technological processes such as thermochemical energy storage [1,2], geochemical phenomena at the mineral/water interfaces [3,4], and durability of glasses and biomaterials [5,6]. A prominent technological application of crystal dissolution is the production of cement and concrete. Cement, as the "adhesive" in concrete, is used worldwide social infrastructures, military and civil buildings, being the most consumed manufactured material. The clinker hydration is the crucial step which controls the final properties of cement materials, and yet, the hydration process of cement minerals are still arguably despite the long lasting research [7]. Due to the large amount of $\mathrm{CO}_{2}$ emissions and energy consumption in cement industry and the increasing demand, understanding cement 
hydration mechanisms is urgently needed to supply an academic basis for the design of new environmentally friendly cements.

Belite ( $\beta$-dicalcium silicate, $\beta$ - $C_{2} S$ in cement chemistry notation) is an artificial orthosilicate that forms during the sintering of cement clinker, yet it has a natural counterpart called Larnite [8] that appears in natural environments. It is one of the most important minerals in cement industry, and has potential advantages for achieving the low carbon emission goal due to its lower sintering temperature and low calcium carbonate resource demanding compared to tricalcium silicate, the base component of traditional cements. However, the low hydration rate of belite restricts its engineering applications. Until now, the experimental endeavours conducted to improve its hydration [9-12] have had a very limited success.

In such scenario, atomistic simulations are a valuable tool as a complement to experiments in order to study the hydration mechanism of materials, as they have demonstrated for ionic solids [13], metallic oxides [14,15], minerals [16-18], or ceramics [19]. Regarding cement, atomistic simulations have been mainly used to investigate tricalcium silicate [20-26], the main component of cement, and much less attention has been paid to $\beta-C_{2} S$ [27-29]. In this article we aim to investigate the interaction between $\beta-C_{2} S$ surface and water molecules from a fundamental point of view, using Density Functional Theory (DFT) simulations. The obtained results will help us to understand the factors that govern $\beta-C_{2} S /$ water interaction, and let us suggest routes to enhance its hydration kinetics.

\section{Materials and Methods}

\subsection{Model Construction}

The crystal structure of $\beta-\mathrm{C}_{2} \mathrm{~S}$ resolved by Mumme [30] was used as the starting point. Based on previous DFT studies $[27,28]$, we decided to use the (100) surface to investigate the water dissociation process. Compare to other lower index cleavages, it has the second lowest cleavage energy, just 0.09 $\mathrm{eV}$ higher than the most stable cleavage (101), and $0.14 \mathrm{eV}$ lower than the third most stable cleavage (010). Analyzing the crystal Wulff's crystal reconstruction, showed in the appendix A, we observed that the contribution of the (100) surface to the equilibrium shape's total surface area is $20 \%$, just $2 \%$ and $1 \%$ smaller than the (101) and (010) surfaces respectively. We do not expect neither a radical different behavior of water adsorption on this surface nor in the crystal hydration due to their comparable properties. However, the (100) surface presents all the atom types with different equivalent positions defined by symmetry exposed to the vacuum, so it can be considered as a good representative cleavage. A slab with dimensions $13.5 \AA$ x $18.6 \AA$ in the periodic directions and $20 \AA$ thick was constructed, with a vacuum layer set to be $16 \AA$, as shown in Fig.1 (a).

\subsection{Computational details}

The DMol3 density functional theory (DFT) package [31] was employed to study the interaction between the slab model and water. The exchange-correlation is treated in the generalized gradient approximation (GGA) with the Perdew-Burke-Ernzerhof (PBE) functional [32]. The treatment for the core electrons is all electrons method. A double $\zeta$ plus polarization (DZP) basis set is used, with a global orbital cut-off radius of $5.5 \AA$. The orbital smearing parameter is set to $0.01 \mathrm{eV}$ to balance precision and computing performance. The k-point grid in the first Brillouin zone is constructed using the Monkhorst-Pack method [33], with a $2 \times 2 \times 1$ k-points grid. Self-consistent iteration convergence precision is set to $2.5 \times 10^{-5} \mathrm{eV}$, the energy convergence tolerance to $2.5 \times 10^{-4} \mathrm{eV}$, and the maximum stress is set to be lower than $0.05 \mathrm{eV} / \AA$. During surface relaxation process a maximum displacement of atoms of $0.005 \AA$ at each step was allowed, and the middle of slab (6.5 ̊ from each surface) atoms were fixed. Furthermore, an external additional potential was applied to correct macroscopic dipole formation [34]. 
Fig. 1(a) depicts the relaxed $\beta-C_{2} S$ (100) surface model described in Section 2.1, together with (b) the projection of the electrostatic potential along the perpendicular direction to the surface. The electrostatic potentials of the upper and bottom surfaces are symmetrical, with a considerable change at the interface where it becomes wider as it extends to the vacuum region. In the middle of vacuum layer, the electrostatic potential matches the vacuum level energy, which indicates that there is no interaction between the upper and lower surfaces. Therefore, the vacuum layer thickness choice is enough to avoid self-interactions.

(a)

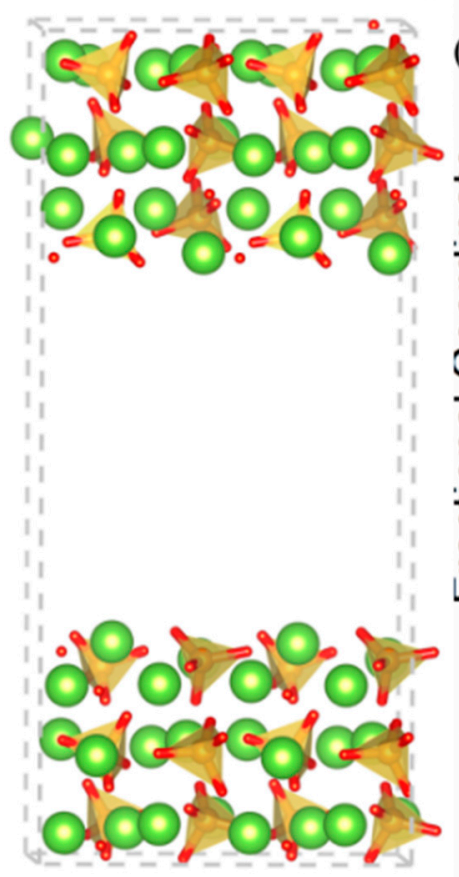

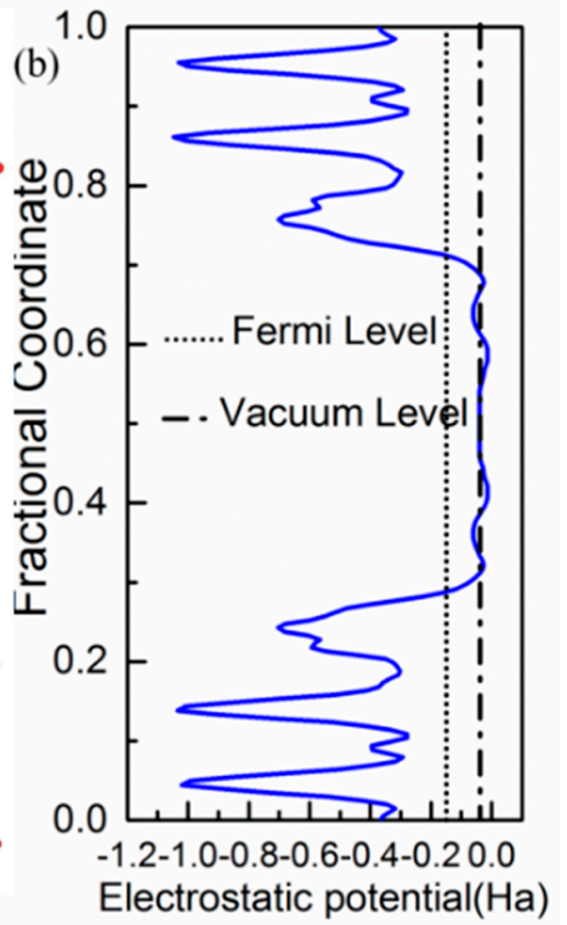

\section{6}

Figure 1 (a) Atomic representation of the $\beta-C_{2} S$ (100) surface model visualized with VESTA[35]. Red, green and orange spheres represent oxygen, calcium and silicate atoms, respectively. The $\mathrm{SiO}_{4}{ }^{-4}$ groups are further represented as orange tetrahedra. (b) Electrostatic potentials along with the vertical vectors of the slab. The solid line represents the vacuum level.

\section{Results}

\subsection{Water adsorption conformation on $\beta-C 2 S$ (100) surface and bonding scheme}

The surface structure of $\beta-C_{2} S$ is quite irregular, with $\mathrm{Ca}$ and $\mathrm{O}$ ions of different symmetry present, silicate ions arranged with different orientations, and a considerable roughness. Therefore, it is more difficult to define "a priori" the water adsorption points on the surface than for symmetrical metal oxides, such as $\mathrm{TiO}_{2}, \mathrm{CaO}, \mathrm{MgO}[14,36,37]$, or two-dimensional materials, such as $\mathrm{Ti}_{2} \mathrm{C}$ [19]. In a previous work [28], water adsorption sites were exhaustively searched using empirical force field methods. Using that information, we have targeted the most favourable adsorption sites of water at $\beta-C_{2} S$, performing an energy minimization on the force field final configuration for each adsorption configuration. It must be noted that the conformation at sites labelled as W2 and W4 were different in the empirical simulation, yet after the present DFT energy minimization they became equivalent.

The investigated sites are shown in Fig. 2, and the corresponding adsorption energies in Table 1. In general, water is adsorbed in a configuration with the oxygen atom $\mathrm{O}(\mathrm{w})$ coordinated to surface calcium atoms $\mathrm{Ca}$, and one of its hydrogen atoms $\mathrm{H}(\mathrm{w})$ pointing towards the surface, forming a hydrogen bond with oxygen atoms $\mathrm{O}(\mathrm{s})$ from the surface silicate groups. The adsorption energies vary in a range from -0.78 to $-1.24 \mathrm{eV}$, which indicates that the surface is considerably hydrophilic 
118

119

120

121

122

123

124

125

126

127

128

129

130

131

and adsorption energetically favourable [38]. In all the reported adsorption sites the water molecule stablishes a single hydrogen bond with $\mathrm{O}(\mathrm{s})$ atoms, with bond lengths smaller than $1.6 \AA$ and $\mathrm{H}(\mathrm{w})$ $\mathrm{O}(\mathrm{w})-\mathrm{O}(\mathrm{s})$ angles below $24^{\circ}$. In water, hydrogen bond distances and angles are typically larger, about $1.9 \AA$ and less than $35^{\circ}$ respectively $[39,40]$. Since the hydrogen bond length and strength are usually correlated [39] this suggests a strong hydrogen bond between water and belite surface. Regarding the $\mathrm{Ca}-\mathrm{O}(\mathrm{w})$ distance, we found that the coordination distances of $\mathrm{Ca}-\mathrm{O}(\mathrm{w})$ on the interface are bellow $2.65 \AA$ which match with the Ca-O coordination distance on bulk $\beta-C_{2} S$ [30].

Based on the described conformations we can suggest a bonding scheme in which $\beta-\mathrm{C}_{2} \mathrm{~S}$ suffers simultaneously both nucleophilic and electrophilic attack from water [22,29]: the $\mathrm{Ca}$ is an electron acceptor from the $\mathrm{O}(\mathrm{w})$ electron donor, and the $\mathrm{O}(\mathrm{s})$ is an electron donor (or proton acceptor) to the $\mathrm{H}(\mathrm{w})$ electron acceptor, forming a hydrogen bond. However, it is quite complex to correlate the magnitude of the adsorption energy as a function of the conformation adopted by water at the surface. Hence, it is necessary to analysis the electronic properties of the adsorbate/substrate system to understand the water adsorption mechanism on the surface.
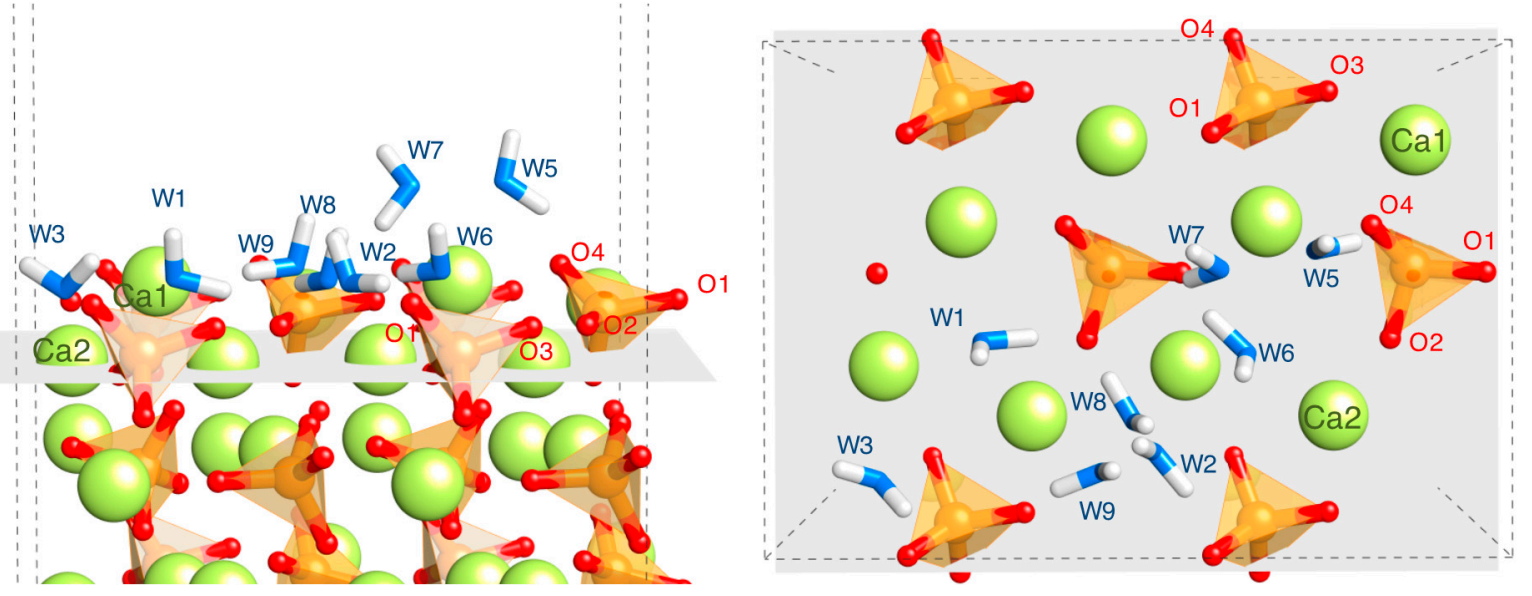

133

134

135

136

137

138

139

140

141

Figure 2 . Water adsorption configurations on the 9 adsorption sites of $\beta-C_{2} S(100)$ in side and top views. The nomenclature of the $\mathrm{Ca}$ and $\mathrm{O}$ sites from dicalcium silicate follow that of the original paper describing the crystalline structure [30]. The atoms representation is the same as in figure 1, including the water molecules with the $\mathrm{O}$ atoms in blue and the $\mathrm{H}$ atoms in white.

Table 1 Hirshfeld charge of water molecule atoms for various adsorption sites as well as the corresponding adsorption energies. The adsorption sites are named from 1 to 9 in descending adsorption energy order, and the surface $\mathrm{Ca}$ and oxygen numbers are thos in figure 2. The water molecule atoms are named with the w subscript. The $\mathrm{H}_{\mathrm{w}}$ taking part of the hydrogen bond (see text) is labeled as $\mathrm{H}_{\mathrm{w}}(\mathrm{O})$

\begin{tabular}{|l|c|c|c|c|c|c|c|c|c|c|}
\hline No. & $\begin{array}{c}\text { Adsorption } \\
\text { Site }\end{array}$ & $\begin{array}{c}\text { Adsorption } \\
\text { Energy (eV) }\end{array}$ & \multicolumn{3}{|c|}{ Hirshfeld charge on water (e-) } & \multicolumn{2}{|c|}{$\begin{array}{c}\text { Hirshfeld charge } \\
\text { on surfaces (e-) }\end{array}$} & $\begin{array}{c}\text { Bond } \\
\text { distance }\end{array}$ & $\begin{array}{c}\text { Bond } \\
\text { distance } \\
\text { O-Hw (Å) }\end{array}$ \\
\hline W1 & Ca1 O4 & -1.24 & -0.198 & 0.099 & 0.180 & 0.081 & 0.612 & -0.321 & 2.595 & 1.419 \\
\hline W2 & Ca2 O3 & -1.14 & -0.195 & 0.108 & 0.181 & 0.094 & 0.477 & -0.361 & 2.644 & 1.598 \\
\hline W3 & Ca2 O3 & -1.14 & -0.196 & 0.107 & 0.179 & 0.09 & 0.475 & -0.362 & 2.630 & 1.593 \\
\hline W4 & Ca2 O3 & -1.14 & -0.198 & 0.106 & 0.179 & 0.087 & 0.476 & -0.362 & 2.630 & 1.392 \\
\hline W5 & Ca1 O2 & -1.09 & -0.269 & 0.101 & 0.169 & 0.001 & 0.649 & -0.356 & 2.351 & 1.550 \\
\hline W6 & Ca2 O1 & -1.07 & -0.218 & 0.095 & 0.176 & 0.053 & 0.446 & -0.218 & 2.542 & 1.393 \\
\hline W7 & Ca1 O1 & -1.00 & -0.258 & 0.108 & 0.174 & 0.024 & 0.649 & -0.258 & 2.395 & 1.661 \\
\hline W8 & Ca2 O4 & -0.91 & -0.203 & 0.103 & 0.177 & 0.077 & 0.462 & -0.203 & 2.560 & 1.524 \\
\hline W9 & Ca1 O1 & -0.78 & -0.207 & 0.122 & 0.182 & 0.097 & 0.498 & -0.207 & 2.546 & 1.677 \\
\hline
\end{tabular}


$\mathrm{H}_{2} \mathrm{O}$

$-0.302$

0.151

0.151

0

\subsection{Charge population analysis}

A Hirshfield population analysis [41] was performed to investigate the atomic charge transfer between the water molecule and the surface. Table 1 gives the computed charges on the water molecule atoms for the adsorption sites as well as the charges on the surface atoms. Compared with the isolated water molecule, the absolute values of the Hirschfeld charges on the water oxygen atoms have decreased in all the adsorption configurations. It suggests electron transfer from $\mathrm{O}(\mathrm{w})$ to $\mathrm{Ca}(\mathrm{s})$ as we proposed before. Regarding the water hydrogen atoms, we can first observe an anisotropy in their charges, due to the formation of a single hydrogen bond between a water and surface oxygen atom. The $\mathrm{H}(\mathrm{w})$ involved in the hydrogen bond is an electron acceptor from the surface $\mathrm{O}(\mathrm{s})$, therefore decreasing its positive charge. The remaining hydrogen, pointing towards the vacuum, increases its charge, possible due to intramolecular electron withdraw from the $\mathrm{O}(\mathrm{w})$ which has donate electrons to the surface. The trend of the Hirshfeld population on the $\beta-C_{2} S(100)$ surface atoms involved in the adsorption corroborate the changes described for the water molecules. There is a positive charge decrease on $\mathrm{Ca}(\mathrm{s})$ due to the electron transfer from $\mathrm{O}(\mathrm{w})$, and a negative charge decrease on the $\mathrm{O}(\mathrm{s})$ due to the electron transfer to the $\mathrm{H}(\mathrm{w})$.

The Hirshfeld population analysis interpretation matches with the proposed bonding scheme. Overall, there is a net positive charge on the adsorbed water molecule, which indicates that the electron depletion of the $\mathrm{O}(\mathrm{w})$ donnor is more important that the electron surfeit of the $\mathrm{H}(\mathrm{w})$. If we consider that the binding energy due to the hydrogen bond represents about $0.22 \mathrm{eV}$, similar to the one between water molecules [42,43], it is clear that most of the adsorption energy gain arises from the $\mathrm{O}(\mathrm{w})-\mathrm{Ca}$ ionic interaction. Hence, the population analysis suggests that the main interaction in the water adsorption is the $\mathrm{O}(\mathrm{w})$-Ca ionic interaction.

\subsection{Partial Density of States}

Hirshfeld population analysis reveals a net electron transfer from the water molecules to the surface. For further understanding of the process, the partial density of states (PDOS) of the $\mathrm{Ca}(\mathrm{s})$ and $\mathrm{O}(\mathrm{s})$ atoms involved in the highest adsorption energy site (W1) and the lowest adsorption energy site (W9) are investigated, before and after water adsorption. In both sites, the p-orbitals from surface $\mathrm{O}$ atoms are the most significant states contributing to the valence band maximum (VBM). This indicates that the under coordinated dangling oxygen atoms on the surface localize the electronic charge, being susceptible for suffering electrophilic attack from water and donate electrons. Regarding the conduction band minimum (CBM), there is a larger contribution of Ca1-s unoccupied states in the of W1 and W9 sites. Hence, the surface Ca atoms are prone of suffering nucleophilic attack and accept electrons. Therefore, the PDOS of the bare surface matches again with the suggested bonding scheme. Overall, the contribution of oxygen p-states to the VBM and the calcium s-states to the CBM is stronger in the W1 sites, which makes them more favorable both for electrophilic and nucleophilic attack, a perfect situation for the adsorption of water molecules, as can be seen from its corresponding adsorption energy.

After water chemisorption, the orbitals of the water molecule are hybridized with both O-p VBM and Ca-s CBM states of the surfaces as shown in fig. 3(c) and (d), respectively. The effect of water is stronger in the CBM than in the VBM, which suggest the Ca-water interaction contributes to the adsorption stabilization more than the hydrogen bond. Furthermore, in the W1 site the CBM is distributed both in the Ca-s and $\mathrm{H}(\mathrm{w})$ unoccupied states, while in the W9 it is strongly localized in the water hydrogen atoms. This suggests that the $\mathrm{H}(\mathrm{w})$ in the W9 has not established a strong hydrogen bond with the $\mathrm{O}(\mathrm{s})$, and therefore still has the capacity to accept electrons. In fact, the 
187

188

189

190

Hirsfeld charge on the $\mathrm{H}(\mathrm{w})$ at the W9 site has suffer the lower decrease with respect to the isolated water, confirming this interpretation. Again, these findings agree with the bonding scheme proposed from previous analysis, and give an explanation of the more favourable water adsotpion in W1 than W9 sites.
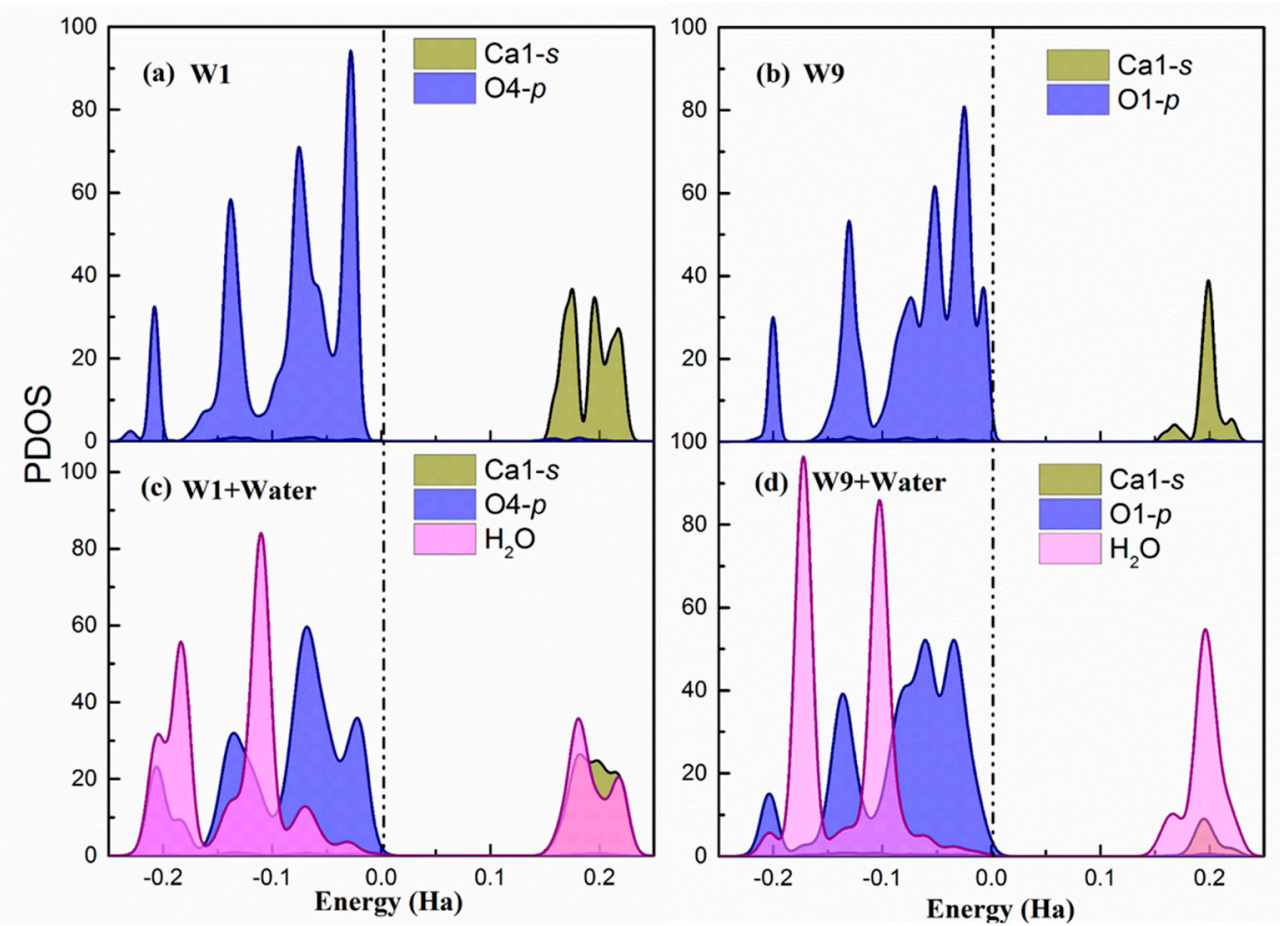

Figure 3. (a) and (b) The partial density of states of W1 and W9 adsorption sites on the relaxed surface; (c) and (d) The partial density of states of W1 and W9 adsorption sites after water adsorbed on the surface. The dash dot line indicates the Fermi level.

\subsection{Chemical bonding from charge density difference analysis}

To complete the characterization of chemical bonding and charge transfer, we move forward to study the spatial electron density distribution before and after the water adsorption from electron density difference, $\Delta \rho$, calculated from the formula:

$$
\Delta \rho=\left(\rho_{\mathrm{H}_{2} \mathrm{O}}+\rho_{\text {surf }}\right)-\rho_{\mathrm{H}_{2} \mathrm{O}+\operatorname{surf}}
$$

where $\rho_{\mathrm{H} 2 \mathrm{O}+\mathrm{surf}}$ represents the electron density distribution of the water adsorbed on the surface; $\rho_{\mathrm{H} 2 \mathrm{O}}$ and $\rho_{\text {surf }}$ are the electron densities of individual water molecules and pure surface respectively. Accordingly, a positive $\Delta \rho$ value in a point indicate a lower electronic density after water adsorption due to electron density depletion, and negative values a higher electronic density due to electron density surfeit. The electron density difference was plotted in Fig. 4, where light and dark blue isosurfaces represent the $\Delta \rho<0$ and $>0$ respectively.

It can be observed that the electron density around the adsorption points of the surface is significantly polarized after the water adsorption, yet the effect is local and only the atoms involved in the adsorption site are affected. In both cases the situation is similar: there is a localized electronic density depletion in the $\mathrm{O}(\mathrm{s})$ atoms that forms the hydrogen bond, as well as a more delocalized depletion in the area of the water oxygen lone pair. On the other hand, the electronic density increment on the $\mathrm{H}(\mathrm{w})$ atoms, and the $\mathrm{Ca}(\mathrm{s})$ atoms shown in Fig. 4(c) and 4(d). It must be noted that the electron density surfeit takes place in more than one $\mathrm{Ca}$ atoms from the surface, so the adsorption site involves an ionic interaction with more than one Ca atom from the surface. From the charge density isosurfaces, it is apparent that the charge transfer is more pronounced on the W1 sites in 
comparison with the W9 sites, which is in agreement with the Hirshfeld populations, the PDOS analysis, and the computed adsorption energies.

Once more, the findings are consistent with the suggested electrophilic-nucleophilic dual adsorption scheme, i.e., the $\mathrm{H}(\mathrm{w})$ being an electron acceptor from the surface $\mathrm{O}$ and the $\mathrm{O}(\mathrm{w})$ being an electron donor to surface $\mathrm{Ca}$ atoms.
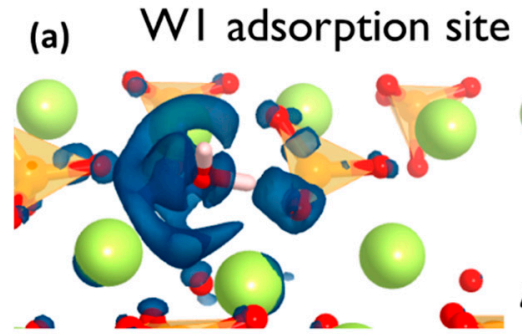

(c)

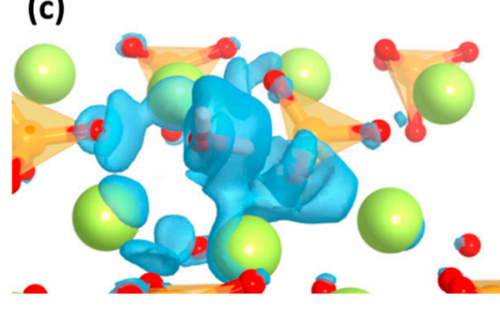

(b) W9 adsorption site

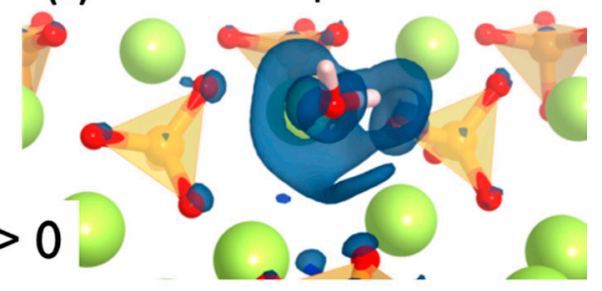

(d)

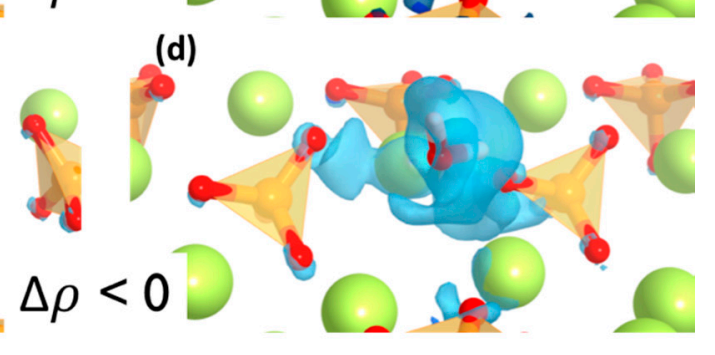

Figure 4. Isosurface plots of the electron density difference for $W 1(a, c)$ and $W 9(b, d)$ adsorption sites. Dark and light blue isosurfaces indicate the electron density depletion and surfeit, respectively.

\section{Conclusions}

$\beta$-dicalcium silicate is a promising candidate to develop low-CO2 cements, yet its slow hydration rate has limited its practical applications so far. In this work density functional theory simulations have been employed with the aim of understanding the water adsorption mechanism on $\beta$-dicalcium silicate (100) surface, and suggest possible routes to enhance its reactivity.

Due to the structural complexity, there are multiple water adsorption sites with different energies on $\beta$-C2S (100) surface. The most favourable adsorption sites are ascribed to the co-existence of a dangling oxygen atom from the silicate group and surface calcium atoms. The structural and electronic analyses point towards a double nucleophilic-electrophilic attack by water molecules to the $\beta$-C2S (100) surface: On the one hand, there is electron transfer from the water molecule oxygen atom to the surface $\mathrm{Ca}$ atoms. On the other hand, one of the water hydrogen atoms establishes a hydrogen bond with the silicate oxygen atoms along with transferring positive charge onto the silicate oxygen atoms. Among these two possibilities, the electronic structure analysis suggests that the interaction between water and the $\beta$-C2S (100) adsorption sites is predominantly governed by the $\mathrm{Ca}$ (surface)-O (water) ionic interaction, in which the surface calcium atoms acts as positive charge donor (electron acceptor) with the interaction of the $\mathrm{O}(\mathrm{w})$ lone pair. In contrast, the hydrogen bond interaction plays a less important role.

These findings are the first step towards rational design high reactive belite crystals. Specifically, we suggest that Frenkel or Schottky point defects could increase the donor and acceptor character of the atoms close to the vacancy, enhancing the interaction with water. Similarly, isovalent chemical substitutions of $\mathrm{Ca}$ or $\mathrm{O}$ by more electropositive and electronegative atoms, or aliovalent substitutions, should create favourable points for water nucleophilic-electrophilic dual interaction. It must be taken into account that the point defects will enhane local affinity for water, yet macroscopic hydration should be also influenced by line, plane, and bulk defects $[7,44]$. 
Acknowledgments: The authors thank the supports of the Project Funded by the National Natural Science Foundation of China (No. 51602148), the Priority Academic Program Development of Jiangsu Higher Education Institutions (PAPD), the Program for Innovative Research Team in University of Ministry of Education of China (No.IRT_15R35), the financial support from the Departamento de Educación, Política Lingüística y Cultura del Gobierno Vasco (IT912-16) and the ELKARTEK project. The technical and human support provided by IZO-SGI SGIker of UPV/EHU and European funding (ERDF and ESF) is also acknowledged.

Author Contributions: "Q.W., H.M. and X.S. conceived and designed the simulations; Q.W. performed the simulations; Q.W. and H.M. analyzed the data; Q.W., H.M. and I.L.wrote the paper."

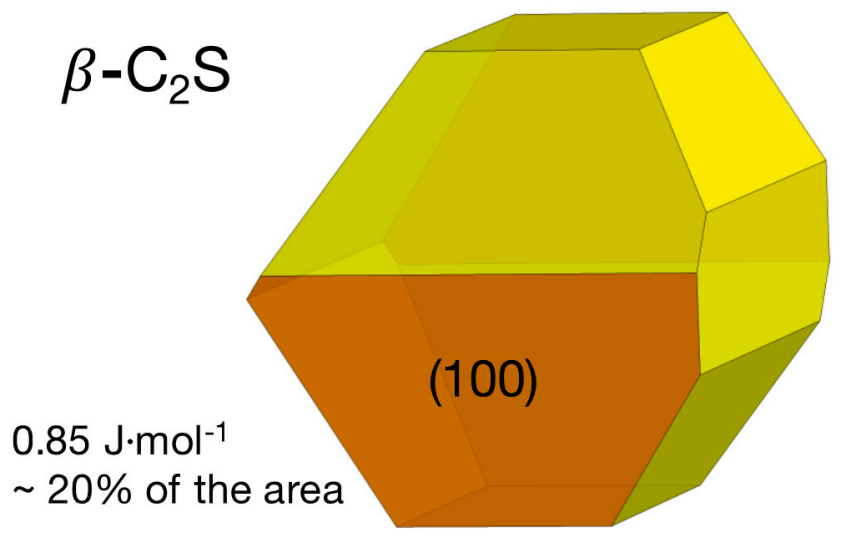

Figure S1. Wulff shape reconstruction of $\beta$ - $\mathrm{C}_{2} \mathrm{~S}$ according to the surfaces energies computed in ref. [28]. The 3 labeled surfaces are the main surfaces in terms of contribution to the total area, and the label shows their cleavage, their contribution to the total surface, and their surface energies. The shape reconstruction and the contribution of each surface to the total area of the crystal has been obtained from the VESTA code [35].

\section{Appendix B}

264 The Hw taking part of the hydrogen bond is labeled as $\mathrm{Hw}(\mathrm{O})$

\begin{tabular}{|c|c|c|c|c|c|c|c|c|}
\hline \multirow[t]{2}{*}{ No. } & \multirow{2}{*}{$\begin{array}{l}\text { Adsorption } \\
\text { Sites }\end{array}$} & \multirow{2}{*}{$\begin{array}{l}\text { Adsorption } \\
\text { Energy (eV) }\end{array}$} & \multicolumn{4}{|c|}{ Hirshfeld charge on water } & \multicolumn{2}{|c|}{$\begin{array}{c}\text { Hirshfeld charge on } \\
\text { surfaces }\end{array}$} \\
\hline & & & Ow & $\mathrm{Hw}(\mathrm{O})$ & Hw & Total & $\mathrm{Ca}(\mathrm{e})$ & Os (e) \\
\hline W1 & Ca1 O4 & -1.24 & -0.198 & 0.099 & 0.180 & 0.081 & 0.612 & -0.321 \\
\hline W2 & $\mathrm{Ca} 2 \mathrm{O} 3$ & -1.14 & -0.195 & 0.108 & 0.181 & 0.094 & 0.477 & -0.361 \\
\hline W3 & $\mathrm{Ca} 2 \mathrm{O} 3$ & -1.14 & -0.196 & 0.107 & 0.179 & 0.09 & 0.475 & -0.362 \\
\hline W4 & $\mathrm{Ca} 2 \mathrm{O} 3$ & -1.14 & -0.198 & 0.106 & 0.179 & 0.087 & 0.476 & -0.362 \\
\hline W5 & $\mathrm{Ca} 1 \mathrm{O} 2$ & -1.09 & -0.269 & 0.101 & 0.169 & 0.001 & 0.649 & -0.356 \\
\hline W6 & $\mathrm{Ca} 2 \mathrm{O} 1$ & -1.07 & -0.218 & 0.095 & 0.176 & 0.053 & 0.446 & -0.218 \\
\hline W7 & Ca1 O1 & -1.00 & -0.258 & 0.108 & 0.174 & 0.024 & 0.649 & -0.258 \\
\hline W8 & $\mathrm{Ca} 2 \mathrm{O} 4$ & -0.91 & -0.203 & 0.103 & 0.177 & 0.077 & 0.462 & -0.203 \\
\hline W9 & $\mathrm{Ca} 1 \mathrm{O} 1$ & -0.78 & -0.207 & 0.122 & 0.182 & 0.097 & 0.498 & -0.207 \\
\hline $\mathrm{H} 2 \mathrm{O}$ & - & - & -0.302 & 0.151 & 0.151 & 0 & - & - \\
\hline $\mathrm{C} 2 \mathrm{~S}$ & Ca1 & & & & & & 0.666 & \\
\hline $\mathrm{C} 2 \mathrm{~S}$ & $\mathrm{Ca} 2$ & & & & & & 0.511 & \\
\hline $\mathrm{C} 2 \mathrm{~S}$ & $\mathrm{O} 1$ & & & & & & & -0.398 \\
\hline $\mathrm{C} 2 \mathrm{~S}$ & $\mathrm{O} 2$ & & & & & & & -0.411 \\
\hline $\mathrm{C} 2 \mathrm{~S}$ & $\mathrm{O} 3$ & & & & & & & -0.412 \\
\hline $\mathrm{C} 2 \mathrm{~S}$ & $\mathrm{O} 4$ & & & & & & & -0.380 \\
\hline \multicolumn{3}{|c|}{ Average charge variation } & 0.086 & -0.046 & 0.026 & 0.067 & -0.036 & 0.045 \\
\hline
\end{tabular}




\section{Appendix C}

Table C1. Interatomic distances between water molecules and surface atoms and intramolecular bond distances for the studied adsorption configurations. The $\mathrm{H}_{\mathrm{w}}$ taking part of the hydrogen bond is labeled as $\mathrm{H}_{\mathrm{w}}(\mathrm{O})$

\begin{tabular}{|c|c|c|c|c|c|c|}
\hline \multirow{2}{*}{ No. } & \multirow{2}{*}{$\begin{array}{l}\text { Adsorption } \\
\text { Sites }\end{array}$} & \multirow{2}{*}{$\begin{array}{l}\text { Adsorption Energy } \\
\qquad(\mathrm{eV})\end{array}$} & \multicolumn{2}{|c|}{ Water-surface distances } & \multicolumn{2}{|c|}{ Intramolecular distances } \\
\hline & & & $\begin{array}{l}\mathrm{Ca}-\mathrm{O}_{\mathrm{w}} \mathrm{H}_{w} \\
\text { (§̊) }\end{array}$ & $\begin{array}{l}\mathrm{O}-\mathrm{H}_{w} \\
\text { (A) }\end{array}$ & $\mathrm{O}_{\mathrm{w}}-\mathrm{H}_{\mathrm{w}}(\mathrm{O})(\AA)$ & $\mathrm{O}_{\mathrm{w}}-\mathrm{H}_{\mathrm{w}}(\AA)$ \\
\hline W1 & $\mathrm{Ca} 1 \mathrm{O} 4$ & -1.24 & 2.595 & 1.419 & 0.99 & 0.85 \\
\hline W2 & $\mathrm{Ca} 2 \mathrm{O} 3$ & -1.14 & 2.644 & 1.598 & 1.08 & 0.84 \\
\hline W3 & $\mathrm{Ca} 2 \mathrm{O} 3$ & -1.14 & 2.630 & 1.593 & 1.07 & 0.88 \\
\hline W4 & $\mathrm{Ca} 2 \mathrm{O} 3$ & -1.14 & 2.630 & 1.392 & 1.06 & 0.83 \\
\hline W5 & $\mathrm{Ca} 1 \mathrm{O} 2$ & -1.09 & 2.351 & 1.550 & 1.01 & 0.76 \\
\hline W6 & $\mathrm{Ca} 2 \mathrm{O} 1$ & -1.07 & 2.542 & 1.393 & 0.95 & 0.81 \\
\hline W7 & $\mathrm{Ca} 1 \mathrm{O} 1$ & -1.00 & 2.395 & 1.661 & 1.08 & 0.81 \\
\hline W8 & $\mathrm{Ca} 2 \mathrm{O} 4$ & -0.91 & 2.560 & 1.524 & 1.03 & 0.81 \\
\hline W9 & Ca1 O1 & -0.78 & 2.546 & 1.677 & 1.22 & 0.84 \\
\hline
\end{tabular}

\section{References}

1. Cot-Gores, J.; Castell, A.; Cabeza, L. F. Thermochemical energy storage and conversion: A-state-of-the-art review of the experimental research under practical conditions. Renew. Sustain. Energy Rev. 2012, 16, 52075224, doi:10.1016/j.rser.2012.04.007.

2. Sharma, A.; Tyagi, V. V; Chen, C. R.; Buddhi, D. Review on thermal energy storage with phase change materials and applications. Renew. Sustain. energy Rev. 2009, 13, 318-345.

3. Ohlin, C. A.; Villa, E. M.; Rustad, J. R.; Casey, W. H. Dissolution of insulating oxide materials at the molecular scale. Nat. Mater. 2010, 9, 11-9, doi:10.1038/nmat2585.

4. Brantley, S. L.; Kubicki, J. D.; White, A. F. Kinetics of water-rock interaction; Springer, 2008; Vol. 168;.

5. Oelkers, E. H. General kinetic description of multioxide silicate mineral and glass dissolution. Geochim. Cosmochim. Acta 2001, 65, 3703-3719, doi:10.1016/S0016-7037(01)00710-4.

6. Porter, A. E.; Patel, N.; Skepper, J. N.; Best, S. M.; Bonfield, W. Comparison of in vivo dissolution processes in hydroxyapatite and silicon-substituted hydroxyapatite bioceramics. Biomaterials 2003, 24, 4609-4620, doi:10.1016/S0142-9612(03)00355-7.

7. Bullard, J. W.; Jennings, H. M.; Livingston, R. A.; Nonat, A.; Scherer, G. W.; Schweitzer, J. S.; Scrivener, K. L.; Thomas, J. J. Mechanisms of cement hydration. Cem. Concr. Res. 2011, 41, 1208-1223.

8. Jost, K. H.; Ziemer, B.; Seydel, R.; H, K. Redetermination of structure of beta-dicalcium silicate. Acta Crystallogr. Sect. B-Structural Sci. 1977, 33, 1696-1700.

9. Fukuda, K.; Ito, S. Improvement in reactivity and grindability of belite-rich cement by remelting reaction. J. Am. Ceram. Soc. 1999, 82, 2177-2180.

10. Cuberos, A. J. M.; De la Torre, A. G.; Martin-Sedeno, M. C.; Moreno-real, L.; Merlini, M.; Ordonez, L. M.; Aranda, M. A. G.; De, Á. G.; Martín-sedeño, M. C.; Ordónez, L. M. Phase development in conventional and active belite cement pastes by Rietveld analysis and chemical constraints. Cem. Concr. Res. 2009, 39, 833842, doi:10.1016/j.cemconres.2009.06.017.

11. Cuberos, A. J. M.; De la Torre, A. G.; Alvarez-Pinazo, G.; Martin-Sedeno, M. C.; Schollbach, K.; Pollmann, 
H.; Aranda, M. A. G. Active Iron-Rich Belite Sulfoaluminate Cements: Clinkering and Hydration. Environ. Sci. Technol. 2010, 44, 6855-6862, doi:10.1021/es101785n.

12. ElDidamony, H.; Sharara, A. M.; Helmy, I. M.; ElAleem, S. A. Hydration characteristics of beta-C2S in the presence of some accelerators. Cem. Concr. Res. 1996, 26, 1179-1187.

13. Yang, H. G.; Sun, C. H.; Qiao, S. Z.; Zou, J.; Liu, G.; Smith, S. C.; Cheng, H. M.; Lu, G. Q. Anatase TiO2 single crystals with a large percentage of reactive facets. Nature 2008, 453, 638-641, doi:10.1038/nature06964.

14. Manzano, H.; Pellenq, R. J. M.; Ulm, F.-J.; Buehler, M. J.; van Duin, A. C. T. Hydration of Calcium Oxide Surface Predicted by Reactive Force Field Molecular Dynamics. Langmuir 2012, 28, 4187-4197, doi:10.1021/la204338m.

15. Raymand, D.; van Duin, A. C. T. T.; Spångberg, D.; Goddard, W. a.; Hermansson, K.; Spangberg, D. Water adsorption on stepped $\mathrm{ZnO}$ surfaces from MD simulation. Surf. Sci. 2010, 604, 741-752, doi:10.1016/j.susc.2009.12.012.

16. Stack, A. G.; Raiteri, P.; Gale, J. D. Accurate Rates of the Complex Mechanisms for Growth and Dissolution of Minerals Using a Combination of Rare-Event Theories. J. Am. Chem. Soc. 2011, 134, 11-14, doi:10.1021/ja204714k.

17. De Leeuw, N. H.; Parker, S. C. Molecular-dynamics simulation of $\mathrm{MgO}$ surfaces in liquid water using a shell-model potential for water. Phys. Rev. B 1998, 58, 13901-13908, doi:10.1103/PhysRevB.58.13901.

18. de Leeuw, N. H.; Parker, S. C.; Catlow, C. R. a.; Price, G. D.; Leeuw, N. H. De Modelling the effect of water on the surface structure and stability of forsterite. Phys. Chem. Miner. 2000, 27, 332-341, doi:10.1007/s002690050262.

19. Cicero, G.; Grossman, J. C.; Catellani, A.; Galli, G. Water at a Hydrophilic Solid Surface Probed by Ab initio Molecular Dynamics: Inhomogeneous Thin Layers of Dense Fluid. J. Am. Chem. Soc. 2005, 127, 6830-6835, doi:10.1021/ja042963u.

20. Manzano, H.; Durgun, E.; López-Arbeloa, I.; Grossman, J. C. J. C. Insight on Tricalcium Silicate Hydration and Dissolution Mechanism from Molecular Simulations. ACS Appl. Mater. Interfaces 2015, 7, 14726-14733, doi:10.1021/acsami.5b02505.

21. Manzano, H.; Durgun, E.; Abdolhosseine Qomi, M. J.; Ulm, F.-J.; Pellenq, R. J. M.; Grossman, J. C. Impact of Chemical Impurities on the Crystalline Cement Clinker Phases Determined by Atomistic Simulations. Cryst. Growth Des. 2011, 11, 2964-2972, doi:10.1021/cg200212c.

22. Durgun, E.; Manzano, H.; Pellenq, R. J. M.; Grossman, J. C. Understanding and Controlling the Reactivity of the Calcium Silicate phases from First Principles. Chem. Mater. 2012, 24, 1262-1267, doi:10.1021/cm203127m.

23. Durgun, E.; Manzano, H.; Kumar, P. V. V; Grossman, J. C. J. C. The Characterization, Stability, and Reactivity of Synthetic Calcium Silicate Surfaces from First Principles. J. Phys. Chem. C 2014, 118, 1521415219, doi:10.1021/jp408325f.

24. Huang, J.; Valenzano, L.; Singh, T. V.; Pandey, R.; Sant, G. Influence of (Al, Fe, Mg) Impurities on Triclinic Ca3SiO5: Interpretations from DFT Calculations. Cryst. Growth Des. 2014, 14, 2158-2171, doi:10.1021/cg401647f.

25. Huang, J.; Wang, B.; Yu, Y.; Valenzano, L.; Bauchy, M.; Sant, G. Electronic Origin of Doping-Induced Enhancements of Reactivity: Case Study of Tricalcium Silicate. J. Phys. Chem. C 2015, 119, 25991-25999, doi:10.1021/acs.jpcc.5b08286.

26. Mishra, R. K.; Flatt, R. J.; Heinz, H. Force Field for Tricalcium Silicate and Insight into Nanoscale Properties: Cleavage, Initial Hydration, and Adsorption of Organic Molecules. J. Phys. Chem. C 2013, 117, 10417-10432, 
doi:10.1021/jp312815g.

27. Wang, Q.; Guo, Y.; Manzano, H.; Lopez-Arbeloa, I.; Shen, X.; Li, F. First-principles study of water adsorption and dissociation on $\beta-\mathrm{C} 2 \mathrm{~S}$ (100). In RILEM InternationalSymposium on Concrete ModelingCONMOD 2014; RILEM publications, 2014.

28. Wang, Q.; Manzano, H.; Guo, Y.; Lopez-Arbeloa, I.; Shen, X. Hydration Mechanism of Reactive and Passive Dicalcium Silicate Polymorphs from Molecular Simulations. J. Phys. Chem. C 2015, 119, 19869-19875, doi:10.1021/acs.jpcc.5b05257.

29. Wang, Q.; Li, F.; Shen, X.; Shi, W.; Li, X.; Guo, Y.; Xiong, S.; Zhu, Q. Relation between reactivity and electronic structure for $\alpha^{\prime} \mathrm{L}-, \beta$ - and $\gamma$-dicalcium silicate: A first-principles study. Cem. Concr. Res. 2014, 57, 28-32, doi:10.1016/j.cemconres.2013.12.004.

30. Mumme, W. G.; Hill, R. J.; Bushnellwye, G.; Segnit, E. R. Rietveld Crystal-Structure Refinements, CrystalChemistry and Calculated Powder Diffraction Data for the Polymorphs of Dicalcium Silicate and Related Phases. Neues Jahrb. Fur Mineral. 1995, 169, 35-68.

31. Delley, B. From molecules to solids with the DMol3 approach. J. Chem. Phys. 2000, 113, 7756-7764.

32. Perdew, J. P.; Burke, K.; Ernzerhof, M. Generalized gradient approximation made simple. Phys. Rev. Lett. 1996, 77, 3865-3868.

33. Monkhorst, H. J.; Pack, J. D. Special points for Brillouin-zone integrations. Phys. Rev. B 1976, 13, 5188-5192.

34. Neugebauer, J.; Scheffler, M. Adsorbate-substrate and adsorbate-adsorbate interactions of $\mathrm{Na}$ and $\mathrm{K}$ adlayers on Al (111). Phys. Rev. B 1992, 46, 16067.

35. Momma, K.; Izumi, F. VESTA: a three-dimensional visualization system for electronic and structural analysis. J. Appl. Crystallogr. 2008, 41, 653-658, doi:10.1107/s0021889808012016.

36. Machesky, M. L.; Predota, M.; Wesolowski, D. J.; Vlcek, L.; Cummings, P. T.; Rosenqvist, J.; Ridley, M. K.; Kubicki, J. D.; Bandura, A. V; Kumar, N. Surface protonation at the rutile (110) interface: explicit incorporation of solvation structure within the refined MUSIC model framework. Langmuir 2008, 24, 1233112339.

37. Allen, J. P.; Parker, S. C.; Price, D. W. Atomistic Simulation of the Surface Carbonation of Calcium and Magnesium Oxide Surfaces. J. Phys. Chem. C 2009, 113, 8320-8328, doi:10.1021/jp810885m.

38. Bolis, V.; Fubini, B.; Marchese, L.; Martra, G.; Costa, D. Hydrophilic and hydrophobic sites on dehydrated crystalline and amorphous silicas. J. Chem. Soc. Faraday Trans. 1991, 87, 497-505, doi:10.1039/FT9918700497.

39. Grabowski, S. J. Hydrogen bonding strength-measures based on geometric and topological parameters. J. Phys. Org. Chem. 2004, 17, 18-31, doi:10.1002/poc.685.

40. Duque-Redondo, E.; Manzano, H.; Epelde-Elezcano, N.; Martínez-Martínez, V.; López-Arbeloa, I. Molecular Forces Governing Shear and Tensile Failure in Clay-Dye Hybrid Materials. Chem. Mater. 2014, 26, 4338-4345, doi:10.1021/cm500661d.

41. Hirshfeld, F. L. Bonded-atom fragments for describing molecular charge densities. Theor. Chim. Acta 1977, 44, 129-138.

42. Grabowski, S. J. What Is the Covalency of Hydrogen Bonding? Chem. Rev. 2011, 111, 2597-2625, doi:10.1021/cr800346f.

43. Elgabarty, H.; Khaliullin, R. Z.; Kühne, T. D. Covalency of hydrogen bonds in liquid water can be probed by proton nuclear magnetic resonance experiments. Nat. Commun. 2015, 6.

44. Juilland, P.; Gallucci, E.; Flatt, R.; Scrivener, K. Dissolution theory applied to the induction period in alite hydration. Cem. Concr. Res. 2010, 40, 831-844, doi:10.1016/j.cemconres.2010.01.012. 